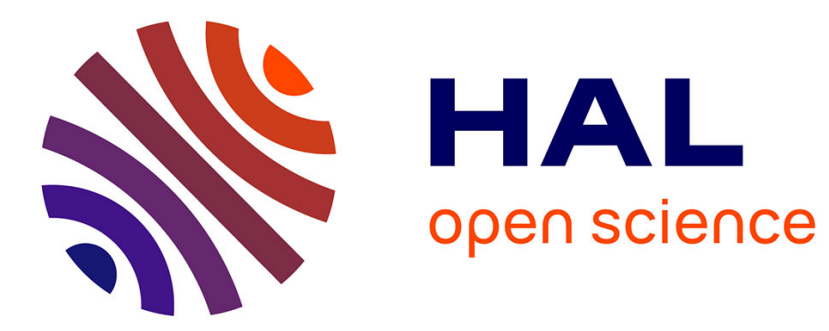

\title{
Socio-economics status and metabolic syndrome: A meta-analysis
}

\author{
M. Blanquet, A. Legrand, A. Pélissier, C. Mourgues
}

\section{To cite this version:}

M. Blanquet, A. Legrand, A. Pélissier, C. Mourgues. Socio-economics status and metabolic syndrome: A meta-analysis. Diabetes and Metabolic Syndrome. Clinical Research and Reviews, 2019, 13, pp.1805 - 1812. 10.1016/j.dsx.2019.04.003 . hal-03484384

\section{HAL Id: hal-03484384 \\ https://hal.science/hal-03484384}

Submitted on 20 Dec 2021

HAL is a multi-disciplinary open access archive for the deposit and dissemination of scientific research documents, whether they are published or not. The documents may come from teaching and research institutions in France or abroad, or from public or private research centers.
L'archive ouverte pluridisciplinaire HAL, est destinée au dépôt et à la diffusion de documents scientifiques de niveau recherche, publiés ou non, émanant des établissements d'enseignement et de recherche français ou étrangers, des laboratoires publics ou privés.

\section{다)(1) $(5$}

Distributed under a Creative Commons Attribution - NonCommerciall 4.0 International 


\section{Title: Socio-economics status and metabolic syndrome: A meta-analysis}

Authors: M. Blanquet ${ }^{1,2}$, A. Legrand ${ }^{1,2}$, A. Pélissier ${ }^{3}$, C. Mourgues $^{4-2}$

${ }^{1}$ Service de Santé Publique, Centre Hospitalo-Universitaire de Clermont-Ferrand, ClermontFerrand, France.

${ }^{2}$ PEPRADE (Périnatalité, grossesse, Environnement, PRAtiques médicales et DEveloppement), EA 4681, Université d'Auvergne, Clermont-Ferrand, France.

${ }^{3}$ LEDi (Laboratoire d'Economie de Dijon), EA 7467, Université Bourgogne Franche-Comté, Dijon, France.

4 DRCI (Délégation à la Recherche Clinique et à l'Innovation), Centre HospitaloUniversitaire de Clermont-Ferrand, Clermont-Ferrand, France.

Corresponding author: C.Mourgues

c_mourgues@chu-clermontferrand.fr

DRCI, 7 Place Henri Dunant 63000 Clermont-Ferrand, France

$+33473750350$

Short title: Socio-economics status and metabolic syndrome

\section{Abbreviations:}

SEG $=$ socio-economic gradient

METs $=$ Metabolic syndrome

HDI= Human Development Index

$\mathrm{WHO}=$ World Health Organization

$\mathrm{IDF}=$ International Diabetes Federation

NECP-ATP III= National Cholesterol Education Program-Adult Treatment Panel III AHA $=$ American Heart Association

$\mathrm{BMI}=$ Body Mass Index 


\section{Disclosure statements:}

\section{Acknowledgements: None}

Financial support: No financial support

Conflict of interest: there is no conflict of interest

\section{Authorship:}

C. Mourgues: redaction of the article, analyses, correspondence between authors, coordination of the work, selection of the reviewed articles, design of the article.

A. Pélissier: redaction of the article, translation in English version and selection of the reviewed article.

A. Legrand: redaction of the article and statistical analyses

M Blanquet: redaction of the article and selection of the reviewed articles.

\section{Ethical standards disclosure:}

"This study was conducted according to the guidelines laid down in the declaration of Helsinki”. Our work is a meta-analysis so we use published data. 


\section{Abstract \\ Objective}

The metabolic syndrome (MetS) is responsible for an increased risk of type 2 diabetes, cardiovascular diseases and is associated with all-cause and cardiovascular mortality. Economic and social vulnerability is not an easy concept to grasp, but some studies investigate the association between MetS and socioeconomic and demographic factors, deprivation (more often correlations rather than causal one due to data). This work aims to assess the association between MetS and socio-economic gradient (SEG) in the literature by performing a meta-analysis.

\section{Design}

The Preferred Reporting Items for Systematic Reviews and Meta-Analyses (PRISMA) statement for systematic reviews were followed.

\section{Setting}

The raw list of studies extracted from PubMed as regard to the inclusion/exclusion criteria was imported in Word. Studies were filed with regard to our three definitions of SEG and their title.

\section{Participants}

Subgroup analysis were performed considering several definitions of Mets: NCEP-ATPIII and IDF2006.

\section{Results}

The overall multivariable-adjusted OR showed that the risk of MetS was significantly increased in association with SEG The results of the subgroup analysis showed an increased risk of MetS in association with SEG when IDF definition was considered.

\section{Conclusions}


Targeted interventions must be implemented in a specific way as prevention campaigns aimed at the general population are generally not adapted to this particular vulnerable population.

\section{Introduction}

The metabolic syndrome (MetS) is a set of physiological and biochemical disorders that includes elevated fasting glucose, high blood pressure, dyslipidaemia, and abdominal obesity. It is responsible for an increased risk of type 2 diabetes, cardiovascular diseases and is associated with all-cause and cardiovascular mortality .

The prevalence of MetS is not easy to measure, suffering from MetS relies on biological tests and physical examination. The prevalence rate of MetS among adults measured in the literature is heterogeneous - mainly ranging from $12 \%$ to $35 \%$. First, the estimates depend on the population studied for examples, Enkh-Oyun et al. (1) estimated the prevalence of MetS at $32.8 \%$ for a representative sample in Mongolia while the prevalence rates for Malaysia is $16.6 \%$ (2).Second, prevalence depends on the definition retained for MetS, in the Turkish adult population prevalence vary from $27.4 \%$ to $36.9 \%$ considering the definition applied (3). There are several guidelines (Table 1): the World Health Organization (WHO 1998) (4), the National Cholesterol Education Program-Adult Treatment Panel III (NECP-ATP III 2005) (5), the American Heart Association (AHA 2005) (6), the International Diabetes Federation (IDF 2006) (18), that why an harmonized definition from IDF/AHA/National Heart Lung and Blood Institute has been performed considering ethnic group's characteristics (2009) (8). Differences between those definitions relate to the number of criteria (blood pressure, triglycerides, HDLC, Fasting glucose BMI or waist circumference). For example WHO definition selected intolerance IGT in addition with 2 or more criteria, IDF (2006) kept abdominal obesity in addition with two others factors too, whereas the others definitions selected 3 or more criteria. 
Economic and social vulnerability is not an easy concept to grasp - and so to measure given its multidimensionality. More precisely, the socio-economic gradient can be understand in several way and can particularly be associated to the concept of social deprivation. Social deprivation has been defined by J. Wrezinski as "the lack of [one or more of the prerequisites of] security, such as a job, enabling individuals and families to assume occupational, family, and social responsibilities and to enjoy basic rights." (9). At the same time, Townsend defined the concept of deprivation as a "state of observable and demonstrable disadvantage relative to the local community or the wider society to which an individual, family or group belongs." He applied this concept to conditions rather than resources and distinguished between deprivation and poverty (10). He also argued that deprivation is the main cause of inequalities in health and developed an index to measure deprivation over given geographic areas (8).

Studies investigate the association - more often correlations rather than causal one due to data limitations - between prevalence of MetS and socio-economic and demographic factors. These studies help to characterize for a given sample the people with higher risk to develop MetS. Variables such as gender, age, income level, education level or marital status are investigated in this literature in order to highlight the existence or not of a socio-economic gradient in the prevalence of MetS. The assumption is that socioeconomic deprivation is associated with Mets. In a review of literature miscellaneous variables were used to define socioeconomic status from one variable to several one and by adding variables or by integrating them into a score.

The diversity in measurement of MetS, sample studied and causal association investigated make difficult to compare and synthetize the results from the literature. This work aims to assess the association between MetS and socio-economic gradient (SEG) in the literature by performing a meta-analysis.

\section{Methods}


The Preferred Reporting Items for Systematic Reviews and Meta-Analyses (PRISMA) statement for systematic reviews were followed(11,12).

\subsection{Search strategy and eligibility criteria}

A systematic review was performed on PubMed, published in English until October 17, 2017 and that assess the association between MetS and SEG. Inclusion criteria were:

(1) MetS was measured in adults (18+ years old) according to at least one of the following definitions: NCEP ATPIII 2001 (5), IDF 2006 (7), WHO 1998 (4), Harmonized definition 2009 (8), AHA 2005 (6) [TABLE 1],

(2) SEG was investigated by three definitions - more or less enlarged -: we targeted (keywords of the research) the links between MetS and: i) psychosocial deprivation, ii) economic status, and iii) socio-economic status (SES)

(3) Only observational quantitative studies were considered (cohort and cross sectional studies).

Exclusion criteria were:

(1) the full-text manuscript was not accessible,

(2) the publication was only in symposium or conference abstracts, book chapters, case reports or letters to the editor.

\subsection{Study selection}

The raw list of studies extracted from PubMed as regard to the inclusion/exclusion criteria was imported in Word. Studies were filed with regard to our three definitions of SEG and their title.

The final list of studies retained for the meta-analysis was set up thanks to a three-step process. First, two independent reviewers (one health economist and one MD with nutrition and health economic skills) screened the title and the abstract of each study listed in the Word file. The disagreements or questions were seen by all the authors together until a consensus 
was reach. Second, two of the authors separately reviewed the full-text manuscripts to check precisely the eligibility criteria and to identify by indirect search from the bibliography others studies likely to meet the eligible criteria. Third, the same procedure (steps 1 and 2) was applied for each of the studies found by indirect search. The final list was imported in Excel. Countries were classified to the Human Development Index (HDI) created by the United Nations Development Program, for estimating country human development level (life expectancy, education level and standard of living).

\subsection{Data extraction and assessment of study quality}

Three of the authors extracted the data. Each study included in the aforementioned final list was analysed independently by at least two of these three authors. The databases that resulted from these analyses were compared and combined into a final one, ready for the metaanalysis. Disagreements were resolved by consensus among all the authors. Data extracted concern [supplementary data]:

(1) study identification (title, name of the two first authors, publication date),

(2) study characteristics (country, city, design of the study, sample size),

(3) sample characteristics,

(4) definition of MetS,

(5) variables measuring SEG (list and definition of the variables),

(6) prevalence of MetS,

(7) limits of the study.

\subsection{Statistical analysis}

The odds ratio (OR) was considered as the common measure of the association between SEG with MetS. Fixed effects models were used to aggregate a mean log OR and $95 \% \mathrm{CI}$ as the meta-analysis included only observational studies. The $\mathrm{I}^{2}$ statistic, which measures the percentage of the total variation across studies due to heterogeneity, was assessed. 
Heterogeneity was considered to be present if $\mathrm{I}^{2}$ was superior to $50 \%$. Publication bias was assessed by Begg rank correlation test.

Subgroup analysis were performed considering several definitions of Mets: NCEP-ATPIII and IDF2006.

All statistical analyses were performed using SAS software (version 9.4, SAS Institute, Cary, NC, 2002-2012).

\section{RESULTS}

\subsection{Study identification and selection}

The direct search by initial keyword «metabolic syndrome » led to 66748 articles, 66031 were excluded as they were not relevant. Given our inclusion/exclusion criteria and the completion of steps 1 and 2 of our methodology (section 2.2), we retained 41 articles: 3 dealing with «MetS and psychosocial deprivation", 18 with "MetS and economical status" and 8 with "MetS and socio-economic status". From these articles, we extracted 32 additional studies by indirect search (step 3 described in section 2.2). Finally, our database for the metaanalysis count 73 articles, as presented in the flow-chart (Figure 1).

\subsection{Study characteristics}

In the 73 studies selected, publication year went from 2003 to 2017. Among them, 15 were longitudinal studies (cohorts) (13-27) and 58 were cross sectional studies (1-3,28-80). Regarding Human Development Index (HDI), 35 studies were set in countries classified as very high (13-17,19,20,22,24-26,28-34,36,39-42,44,48,49,51,52,62,64,66,72,77,78,80); 23 in countries classified as high (1-3,21,28,35,37,42,43,45$47,50,57,58,60,65,67,68,71,73,76,81), 14(18,27,38,53-56,59,63,69,70,74,79,82)$ in countries classified as mid and 1 (61) in a country classified as low. The sample size ranged from 374 to 217216 for a total number of 561 758. Several definition of MetS were used: 20 studies used 
IDF 2006 definition, 48 used NCEP-ATPIII, 7 used 2009 harmonized definition, 14 used AHA 2005 and 7 used another definition WHO 1998 (or incomplete definition compared with those reported in table 1).

\subsection{Socioeconomic gradient and MetS}

Results are presented in figures 2, 3, 4 and 5. The overall multivariable-adjusted OR showed that the risk of MetS was significantly increased in association with SEG $(\mathrm{OR}=1,15$, $95 \% \mathrm{CI}=1,12-1,18$,$) , a substantial level of heterogeneity was observed among studies$ $(\mathrm{p}<0.0001, \mathrm{I} 2=98.2)$. No publication bias was observed according to Begg test $(\mathrm{p}=0.37)$ (figure 2).

The results of the subgroup analysis based on definition of MetS showed an increased risk of MetS in association with SEG when IDF definition was considered $(\mathrm{OR}=1,16$, $95 \% \mathrm{CI}=1,02-1,33)$ with a substantial level of heterogeneity among studies $\left(\mathrm{p}=0.03, \mathrm{I}^{2}=84.3\right)$. No publication bias was observed according to Begg test $(\mathrm{p}=0.25)$ (figure 3 ).

The same association was found when NCEP-ATPIII was used $(\mathrm{OR}=1,21,95 \% \mathrm{CI}=1,17$ $1,25)$ with a substantial level of heterogeneity among studies $\left(p<0.0001, \mathrm{I}^{2}=98.8\right)$. No publication bias was observed according to Begg test $(\mathrm{p}=0.25)$ (figure 4).

However, no association was found when considering the other definitions of MetS and SEG (OR=1.04, 95\%CI=1.00-1.09) (figure 5).

\section{DISCUSSION}

We conducted a meta-analysis over 73 articles on the link between SEG and MetS. Our study showed that economic and social vulnerability, i.e. low SEG measured as regard to psychosocial deprivation, economical status and SES, is a risk associated with Mets.

More precisely, 62 studies of our database underlined this positive association between SEG and MetS. The 11 that did not were mostly cross-sectional studies with low sample size 
( $<1000$ individuals), suggesting that they probably lacked statistical power to put in light a significant correlation between SEG and MetS. Interestingly, our results seemed to be robust. The link we underlined between SEG and MetS was significant and positive whatever the characteristics of the studies (e.g. design, HDI of the country) and the definitions retained for SEG and MetS (IDF or NCEP-ATPIII).

To our knowledge, this meta-analysis is the first one of the link between economic and social vulnerability and MetS. Thus, our study provides a comprehensive list of articles that deal with SES and MetS through our systematic review and synthesizes the existing results through our meta-analysis.

Given the prevalence of MetS is increasing in recent years (83), identifying population-at-risk would participate to a more effective screening and prevention (primary and secondary), particularly when this population-at-risk is also a population concerned by a low access to healthcare services. It has been demonstrated that economic and social vulnerability is a risk factor for various pathologies, particularly for cardiovascular diseases (84) . In our study, SEG appears as an independent factor of MetS. This is an expected result as the prevalence of obesity and of type 2 diabetes is higher in the vulnerable population than in general population. Obesity if one of the components of MetS and MetS is also a risk factor for type 2 diabetes.

Our results must be nuanced. First, during the study selection phase, 81 studies met the inclusion criteria but for six of them the necessary data were not available. Second, regarding the definition of MetS, studies mainly retained the definition of NCEP-ATPIII or that of IDF. We analysed them independently and as we pointed out above, they gave the same results than the global analysis. We examined also the others definitions of MetS, within a unique sub-sample (given the low number of studies concerned by each definition): the link between SES and MetS was not significant. Such a result can be explained by the heterogeneity of the 
definitions that can led to bias in the ranking of the studied population with regard to the definitions of the scientific and international societies. Third, there is no unique definition for economic and social vulnerability. It can be economic, social or psychosocial. An analysis per type of vulnerability could show different links with MetS in terms of significance, sign and magnitude. In our study, we were unable to do this sub-sample analysis, as the number of studies for some definitions was too small. Fourth, the measure of consistency in our metaanalysis $\left(\mathrm{I}^{2}\right)$ showed there was a great heterogeneity among our pool of studies. Lastly, our meta-analysis focused only on the link between SEG and MetS. Further analysis would be required to take into account other potential confounding factors known to be linked to the risk of Mets including gender, age and education level. The data included in the analysis were aggregated data, only the marginal totals were available so that individual characteristics could not be assessed.

\section{CONCLUSION}

Economic and social vulnerability is associated with Mets. Further publications are necessary to confirm those results with harmonized definitions of both Mets and economic and social vulnerability. Targeted interventions must be implemented as prevention campaigns aimed at the general population are not adapted to this particular vulnerable population.

\section{KEYWORDS}

Meta -analysis, metabolic syndrome, economic gradient, lifestyle 


\section{REFERENCES}

1. Enkh-Oyun T, Kotani K, Davaalkham D, et al. Epidemiologic features of metabolic syndrome in a general Mongolian population. Metab Syndr Relat Disord. mai 2015;13(4):179-86.

2. Tan AKG, Dunn RA, Yen ST. Ethnic disparities in metabolic syndrome in malaysia: an analysis by risk factors. Metab Syndr Relat Disord. déc 2011;9(6):441-51.

3. Soysal A, Şimşek H, Doğanay S, et al. Prevalence of Metabolic Syndrome and Affecting Factors among Individuals Aged 30 and over in Balçova District of İzmir. Balkan Med J. mai 2016;33(3):331-8.

4. prelims - whr98_en.pdf [Internet]. [cité 17 avr 2018]. Disponible sur: http://www.who.int/whr/1998/en/whr98_en.pdf

5. ATP III Guidelines At-A-Glance Quick Desk Reference - atglance.pdf [Internet]. [cité 17 avr 2018]. Disponible sur: https://www.nhlbi.nih.gov/files/docs/guidelines/atglance.pdf

6. 2005 American Heart Association (AHA) guidelines for cardiopulmonary resuscitation (CPR) and emergency cardiovascular care (ECC) of pediatric and n... - PubMed - NCBI [Internet]. [cité $17 \quad$ avr 2018]. Disponible sur: https://www.ncbi.nlm.nih.gov/pubmed/16651298

7. Consensus statements [Internet]. [cité 17 avr 2018]. Disponible sur: https://www.idf.org/e-library/consensus-statements/60-idfconsensus-worldwidedefinitionof-the-metabolic-syndrome

8. Alberti KGMM, Eckel RH, Grundy SM, et al. Harmonizing the metabolic syndrome: a joint interim statement of the International Diabetes Federation Task Force on Epidemiology and Prevention; National Heart, Lung, and Blood Institute; American Heart Association; World Heart Federation; International Atherosclerosis Society; and International Association for the Study of Obesity. Circulation. 20 oct 2009;120(16):1640-5.

9. Wrezinski J. Grande pauvreté et précarité économique et sociale. Conseil Economique et Social; 1987 p. 113. (Journal Officiel de la République Française). Report No.: 6.

10. Townsend P. Deprivation. Journal of Social Policy. avr 1987;16(02):125-146.

11. Banzi R, Moja L, Liberati A, et al. Measuring the impact of evidence: the Cochrane systematic review of organised stroke care. Intern Emerg Med. déc 2009;4(6):507-10.

12. Moher D, Stewart L, Shekelle P. All in the Family: systematic reviews, rapid reviews, scoping reviews, realist reviews, and more. Syst Rev. 22 déc 2015;4:183.

13. Carnethon MR, Loria CM, Hill JO,et al. Risk factors for the metabolic syndrome: the Coronary Artery Risk Development in Young Adults (CARDIA) study, 1985-2001. Diabetes care. 2004;27(11):2707-2715. 
14. Prescott E, Godtfredsen N, Osler M, et al. Social gradient in the metabolic syndrome not explained by psychosocial and behavioural factors: evidence from the Copenhagen City Heart Study*. European Journal of Cardiovascular Prevention \& Rehabilitation. 2007;14(3):405-412.

15. Ramsay SE, Whincup PH, Morris $\mathrm{R}$, et al. Is socioeconomic position related to the prevalence of metabolic syndrome?: influence of social class across the life course in a population-based study of older men. Diabetes Care. déc 2008;31(12):2380-2.

16. Chichlowska KL, Rose KM, Diez-Roux AV, et al. Life course socioeconomic conditions and metabolic syndrome in adults: the Atherosclerosis Risk in Communities (ARIC) Study. Annals of epidemiology. 2009;19(12):875-883.

17. Lidfeldt J, Nyberg P, Nerbrand C, et al. Socio-demographic and psychosocial factors are associated with features of the metabolic syndrome. The Women's Health in the Lund Area (WHILA) study. Diabetes Obes Metab. mars 2003;5(2):106-12.

18. Phillips AC, Carroll D, Thomas GN, et al. The influence of multiple indices of socioeconomic disadvantage across the adult life course on the metabolic syndrome: the Vietnam Experience Study. Metab Clin Exp. août 2010;59(8):1164-71.

19. Silventoinen K, Pankow J, Jousilahti $\mathrm{P}$, et al. Educational inequalities in the metabolic syndrome and coronary heart disease among middle-aged men and women. International Journal of Epidemiology. 2005;34(2):327-334.

20. Perel P, Langenberg C, Ferrie J, et al. Household wealth and the metabolic syndrome in the Whitehall II study. Diabetes care. 2006;29(12):2694-2700.

21. Silveira VMF da, Horta BL, Gigante DP, et al. Metabolic syndrome in the 1982 Pelotas cohort: effect of contemporary lifestyle and socioeconomic status. Arquivos Brasileiros de Endocrinologia \& Metabologia. 2010;54(4):390-397.

22. Langenberg C, Kuh D, Wadsworth MEJ, et al. Social circumstances and education: life course origins of social inequalities in metabolic risk in a prospective national birth cohort. Am J Public Health. déc 2006;96(12):2216-21.

23. Yang X, Tao Q, Sun F, et al. The impact of socioeconomic status on the incidence of metabolic syndrome in a Taiwanese health screening population. International journal of public health. 2012;57(3):551-559.

24. Scuteri A, Vuga M, Najjar SS, et al. Education eclipses ethnicity in predicting the development of the metabolic syndrome in different ethnic groups in midlife: the Study of Women's Health Across the Nation (SWAN). Diabetic Medicine. 2008;25(12):13901399.

25. Dallongeville J, Cottel D, Ferrières J, et al. Household income is associated with the risk of metabolic syndrome in a sex-specific manner. Diabetes care. 2005;28(2):409-415.

26. Matthews KA, Räikkönen K, Gallo L, et al. Association between socioeconomic status and metabolic syndrome in women: testing the reserve capacity model. Health Psychology. 2008;27(5):576. 
27. Sy RG, Llanes EJB, Reganit PFM, et al. Socio-demographic factors and the prevalence of metabolic syndrome among filipinos from the LIFECARE cohort. Journal of atherosclerosis and thrombosis. 2014;21(Supplement1):S9-S17.

28. Yang JJ, Yoon H-S, Lee S-A, et al. Metabolic syndrome and sex-specific socioeconomic disparities in childhood and adulthood: the Korea National Health and Nutrition Examination Surveys. Diabet Med. nov 2014;31(11):1399-409.

29. Riediger ND, Clara I. Prevalence of metabolic syndrome in the Canadian adult population. CMAJ. 18 oct 2011;183(15):E1127-1134.

30. Setayeshgar S, Whiting SJ, Vatanparast H. Metabolic syndrome in canadian adults and adolescents: prevalence and associated dietary intake. ISRN Obes. 2012;2012:816846.

31. Blanquet M, Debost-Legrand A, Gerbaud L, et al. Metabolic syndrome and social deprivation: results of a French observational multicentre survey. Fam Pract. févr 2016;33(1):17-22.

32. Park HS, Oh SW, Cho S-I, et al. The metabolic syndrome and associated lifestyle factors among South Korean adults. Int J Epidemiol. avr 2004;33(2):328-36.

33. Park S-J, Kang H-T, Nam C-M, et al. Sex differences in the relationship between socioeconomic status and metabolic syndrome: the Korean National Health and Nutrition Examination Survey. Diabetes Res Clin Pract. juin 2012;96(3):400-6.

34. Park MJ, Yun KE, Lee GE, et al. A cross-sectional study of socioeconomic status and the metabolic syndrome in Korean adults. Annals of epidemiology. 2007;17(4):320-326.

35. Erem C, Hacihasanoglu A, Deger O, et al. Prevalence of metabolic syndrome and associated risk factors among Turkish adults: Trabzon MetS study. Endocrine. 2008;33(1):9-20.

36. Alkerwi A, Donneau A-F, Sauvageot N, et al. Dietary, behavioural and socio-economic determinants of the metabolic syndrome among adults in Luxembourg: findings from the ORISCAV-LUX study. Public health nutrition. 2012;15(5):849-859.

37. Wu HF, Tam T, Jin L, et al. Age, gender, and socioeconomic gradients in metabolic syndrome: biomarker evidence from a large sample in Taiwan, 2005-2013. Ann Epidemiol. mai 2017;27(5):315-322.e2.

38. Kunii D, Hung NTK, Sakai T, et al. The metabolic syndrome: prevalence and risk factors in the urban population of Ho Chi Minh City. Diabetes research and clinical practice. 2005;67(3):243-250.

39. Loucks EB, Magnusson KT, Cook S, et al. Socioeconomic position and the metabolic syndrome in early, middle, and late life: evidence from NHANES 1999-2002. Annals of epidemiology. 2007;17(10):782-790.

40. La Rosa E, Le Clésiau H, Valensi P. Metabolic syndrome and psychosocial deprivation. Data collected from a Paris suburb. Diabetes Metab. avr 2008;34(2):155-61. 
41. Salsberry PJ, Corwin E, Reagan PB. A complex web of risks for metabolic syndrome: race/ethnicity, economics, and gender. Am J Prev Med. août 2007;33(2):114-20.

42. Santos AC, Ebrahim S, Barros H. Gender, socio-economic status and metabolic syndrome in middle-aged and old adults. BMC Public Health. 2008;8(1):62.

43. Azimi-Nezhad M, Ghayour-Mobarhan M, Parizadeh MR, et al. Prevalence of type 2 diabetes mellitus in Iran and its relationship with gender, urbanisation, education, marital status and occupation. Singapore Med J. juill 2008;49(7):571-6.

44. Chichlowska KL, Rose KM, Diez-Roux AV, et al. Individual and Neighborhood Socioeconomic Status Characteristics and Prevalence of Metabolic Syndrome. The Atherosclerosis Risk in Communities (ARIC) Study. Psychosomatic medicine. 2008;70(9):986.

45. Franco GPP, Scala LCN, Alves CJ, et al.. Metabolic syndrome in patients with high blood pressure in Cuiabá-Mato Grosso State: prevalence and associated factors. Arquivos brasileiros de cardiologia. 2009;92(6):472-478.

46. Allal-Elasmi M, Taieb SH, Hsairi M, et al. The metabolic syndrome: prevalence, main characteristics and association with socio-economic status in adults living in Great Tunis. Diabetes \& metabolism. 2010;36(3):204-208.

47. Zuo H, Shi Z, Hu X, et al. Prevalence of metabolic syndrome and factors associated with its components in Chinese adults. Metabolism-Clinical and Experimental. 2009;58(8):1102-1108.

48. Lucove JC, Kaufman JS, James SA. Association between adult and childhood socioeconomic status and prevalence of the metabolic syndrome in African Americans: the Pitt County Study. Am J Public Health. févr 2007;97(2):234-6.

49. Sidorenkov O, Nilssen O, Brenn T, et al. Prevalence of the metabolic syndrome and its components in Northwest Russia: the Arkhangelsk study. BMC Public Health. 2010;10(1):23.

50. Ferguson TS, Tulloch-Reid MK, Younger NO, et al. Prevalence of the metabolic syndrome and its components in relation to socioeconomic status among Jamaican young adults: a cross-sectional study. BMC Public Health. 2010;10(1):307.

51. Manuck SB, Phillips J, Gianaros PJ, et al. Subjective socioeconomic status and presence of the metabolic syndrome in midlife community volunteers. Psychosomatic medicine. 2010;72(1):35.

52. Agyemang C, van Valkengoed I, Hosper K, et al. Educational inequalities in metabolic syndrome vary by ethnic group: evidence from the SUNSET study. International journal of cardiology. 2010;141(3):266-274.

53. Khanam MA, Qiu C, Lindeboom W, et al. The metabolic syndrome: prevalence, associated factors, and impact on survival among older persons in rural Bangladesh. PLoS ONE. 2011;6(6):e20259. 
54. Sirdah MM, Al Laham NA, Ghali ASA. Prevalence of metabolic syndrome and associated socioeconomic and demographic factors among palestinian adults (20-65 years) at the Gaza Strip. Diabetes \& Metabolic Syndrome: Clinical Research \& Reviews. 2011;5(2):93-97.

55. Villamor E, Finan CC, Ramirez-Zea M, et al. Nine Mesoamerican Countries Metabolic Syndrome Study (NiMeCoMeS) Group. Prevalence and sociodemographic correlates of metabolic syndrome in school-aged children and their parents in nine Mesoamerican countries. Public Health Nutr. févr 2017;20(2):255-65.

56. Chakraborty SN, Roy SK, Rahaman MA. Epidemiological predictors of metabolic syndrome in urban West Bengal, India. Journal of family medicine and primary care. 2015;4(4):535.

57. Gannar F, de León AC, Díaz BB, et al. Social class and metabolic syndrome in populations from Tunisia and Spain. Diabetology \& metabolic syndrome. 2015;7(1):88.

58. Lao XQ, Ma WJ, Sobko T, et al. Dramatic escalation in metabolic syndrome and cardiovascular risk in a Chinese population experiencing rapid economic development. BMC Public Health. 2014;14(1):983.

59. Binh TQ, Phuong PT, Nhung BT, et al. Metabolic syndrome among a middle-aged population in the Red River Delta region of Vietnam. BMC Endocr Disord. 26 sept 2014;14:77.

60. Zhao Y, Yan H, Yang R, et al. Prevalence and determinants of metabolic syndrome among adults in a rural area of Northwest China. PLoS ONE. 2014;9(3):e91578.

61. Adedoyin RA, Afolabi A, Adegoke OO, et al. Relationship between socioeconomic status and metabolic syndrome among Nigerian adults. Diabetes \& Metabolic Syndrome: Clinical Research \& Reviews. 2013;7(2):91-94.

62. Navarro M del C, Saavedra P, Jódar E, et al. Osteoporosis and metabolic syndrome according to socio-economic status, contribution of PTH, vitamin D and body weight: The Canarian Osteoporosis Poverty Study (COPS). Clinical endocrinology. 2013;78(5):681-686.

63. Kaduka LU, Kombe Y, Kenya E, Kuria E, Bore JK, Bukania ZN, et al. Prevalence of metabolic syndrome among an urban population in Kenya. Diabetes Care. avr 2012;35(4):887-93.

64. Martin A, Neale EP, Batterham M, et al. Identifying metabolic syndrome in a clinical cohort: Implications for prevention of chronic disease. Prev Med Rep. déc 2016;4:5026.

65. Gharipour M, Sadeghi M, Nouri F, et al. Socioeconomic determinants and metabolic syndrome: Results from the Isfahan Healthy Heart Program. Acta Bio Medica Atenei Parmensis. 2017;87(3):291-198. 
66. Bolanowski J, Bronowicz J, Bolanowska B, et al. Impact of education and place of residence on the risk of metabolic syndrome in Polish men and women. International journal of cardiology. 2010;145(3):542-544.

67. Gronner MF, Bosi PL, Carvalho AM, et al. Prevalence of metabolic syndrome and its association with educational inequalities among Brazilian adults: a population-based study. Brazilian Journal of Medical and Biological Research. juill 2011;44(7):713-9.

68. Belfki H, Ali SB, Aounallah-Skhiri H, et al. Prevalence and determinants of the metabolic syndrome among Tunisian adults: results of the Transition and Health Impact in North Africa (TAHINA) project. Public health nutrition. 2013;16(4):582-590.

69. Jesmin S, Islam MR, Islam AMS, et al. Comprehensive assessment of metabolic syndrome among rural Bangladeshi women. BMC Public Health. 19 janv 2012;12:49.

70. Rguibi M, Belahsen R. Metabolic syndrome among Moroccan Sahraoui adult women. American Journal of Human Biology. 2004;16(5):598-601.

71. Marquezine GF, Oliveira CM, Pereira AC, et al. Metabolic syndrome determinants in an urban population from Brazil: social class and gender-specific interaction. Int J Cardiol. 26 sept 2008;129(2):259-65.

72. Al-Daghri NM, Alkharfy KM, Al-Attas OS, et al. Gender-dependent associations between socioeconomic status and metabolic syndrome: a cross-sectional study in the adult Saudi population. BMC Cardiovasc Disord. 14 avr 2014;14:51.

73. Moreira GC, Cipullo JP, Ciorlia LAS, et al. Prevalence of metabolic syndrome: association with risk factors and cardiovascular complications in an urban population. PLoS ONE. 2014;9(9):e105056.

74. Deedwania PC, Gupta R, Sharma KK, et al. High prevalence of metabolic syndrome among urban subjects in India: a multisite study. Diabetes \& Metabolic Syndrome: Clinical Research \& Reviews. 2014;8(3):156-161.

75. Ebrahimi H, Emamian $\mathrm{MH}$, Shariati $\mathrm{M}$, et al. Metabolic syndrome and its risk factors among middle aged population of Iran, a population based study. Diabetes \& Metabolic Syndrome: Clinical Research \& Reviews. 2016;10(1):19-22.

76. Zhan Y, Yu J, Chen R, et al. Socioeconomic status and metabolic syndrome in the general population of China: a cross-sectional study. BMC Public Health. 2012;12(1):921.

77. Sygnowska E, Piwońska A, Waśkiewicz A, et al. Socioeconomic factors and the risk of metabolic syndrome in the adult Polish population: the WOBASZ study. Kardiologia Polska (Polish Heart Journal). 2012;70(7):718-727.

78. Lekoubou A, Ovbiagele B, Markovic D, et al. Age, sex, and race/ethnic temporal trends in metabolic syndrome prevalence among individuals with myocardial infarction or stroke in the United States. Journal of the neurological sciences. 2017;376:24-28.

79. Ni L-F, Dai Y-T, Su T-C, et al. Substance use, gender, socioeconomic status and metabolic syndrome among adults in Taiwan. Public Health Nursing. 2013;30(1):18-28. 
80. Cho KI, Kim BH, Je HG, et al. Gender-Specific Associations between Socioeconomic Status and Psychological Factors and Metabolic Syndrome in the Korean Population: Findings from the 2013 Korean National Health and Nutrition Examination Survey. Biomed Res Int. 2016;2016:3973197.

81. Sritara P. Prevalence and factors associated with metabolic syndrome among a group of Thai working population: a cross sectional study. J Med Assoc Thai. 2013;96(5):S1.

82. Mangat C, Goel N, Walia DK, et al. Metabolic Syndrome: a challenging health Issue in highly urbanized Union Territory of north India. Diabetology \& Metabolic Syndrome. 23 mars 2010;2:19.

83. Shin D, Kongpakpaisarn K, Bohra C. Trends in the prevalence of metabolic syndrome and its components in the United States 2007-2014. International Journal of Cardiology. 15 mai 2018;259:216-9.

84. Havranek EP, Mujahid MS, Barr DA, et al. Social Determinants of Risk and Outcomes for Cardiovascular Disease: A Scientific Statement From the American Heart Association. Circulation. 1 sept 2015;132(9):873-98.

\section{Tables}


Table 1: Definitions of the Metabolic Syndrome

\begin{tabular}{|c|c|c|c|c|c|}
\hline & WHO 1998 & $\begin{array}{l}\text { NCEP-ATP III } \\
01\end{array}$ & AHA 2005 & IDF 2006 & $\begin{array}{l}\text { Harmonized definition } \\
009\end{array}$ \\
\hline $\begin{array}{l}\text { Metabolic } \\
\text { Syndrome }\end{array}$ & $\begin{array}{l}\text { Glucose intolerance, } \\
\text { IGT or T2D and/or } \\
\text { R } \\
+2 \text { or more criteria }\end{array}$ & 3 or more criteria & $\begin{array}{l}3 \text { or more } \\
\text { criteria }\end{array}$ & $\begin{array}{l}\text { Abdominal obesity } \\
+2 \text { other factors }\end{array}$ & 3 or more criteria \\
\hline $\begin{array}{l}\text { Waist to hip } \\
\text { ratio } \\
\text { And/or BMI }\end{array}$ & $\begin{array}{l}\mathrm{M}>0.90 ; \mathrm{W}>0.85 \\
>30 \mathrm{~kg} / \mathrm{m}^{2}\end{array}$ & & & & \\
\hline $\begin{array}{l}\text { Waist } \\
\text { Circumference } \\
(\mathrm{cm})\end{array}$ & & $\begin{array}{l}\mathrm{M}>102 \\
\mathrm{~W}>88\end{array}$ & $\begin{array}{l}\mathrm{M}>102 \\
\mathrm{~W}>88\end{array}$ & $\begin{array}{l}\text { Europe: } \mathrm{M} \geq 94 ; \mathrm{W} \geq 80 \\
\text { South Asians/Chinese: } \\
\mathrm{M} \geq 90 ; \mathrm{W} \geq 80 \\
\text { Japanese: } \mathrm{M} \geq 85 ; \mathrm{W} \geq\end{array}$ & $\begin{array}{l}\text { Population- and } \\
\text { Country-specific definitions }\end{array}$ \\
\hline $\begin{array}{c}\text { Blood } \\
\text { Pressure }(\mathrm{mmHg})\end{array}$ & $\geq 160-90$ & $\geq 130 / 85$ & $\begin{array}{l}\geq 130 / 85 \\
\text { or med for HBP }\end{array}$ & $\begin{array}{l}\mathrm{sBP} \geq 130 \text { or } \mathrm{dBP} \geq 85 \\
\text { or med for } \mathrm{HBP}\end{array}$ & $\begin{array}{l}\mathrm{sBP} \geq 130 \text { and/or } \mathrm{dBP} \geq 85 \\
\text { or med for } \mathrm{HBP}\end{array}$ \\
\hline $\begin{array}{l}\text { Triglycerides } \\
\mathrm{mmol} / \mathrm{l} \\
(\mathrm{mg} / \mathrm{dL})\end{array}$ & $\geq 1.7(150)$ & $\geq 1.7$ & $\geq 1.7$ & $\geq 1.7$ or med for HTG & $\geq 1.7$ or med for HTG \\
\hline HDL-C & HTG and/or & $\mathrm{M}<1.0 ; \mathrm{W}<1.3$ & $\mathrm{M}<1.0 ; \mathrm{W}<1.3$ & $\mathrm{M}<1.0(40) ; \mathrm{W}<1.3(50)$ & $\mathrm{M}<1.0 ; \mathrm{W}<1.3$ \\
\hline
\end{tabular}




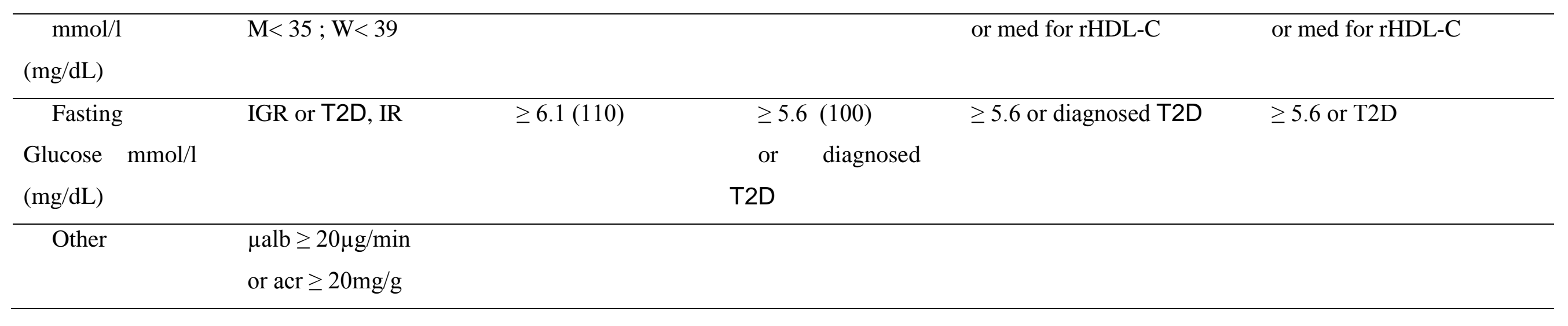


Figures : 
Figure 1: meta-analysis flow chart

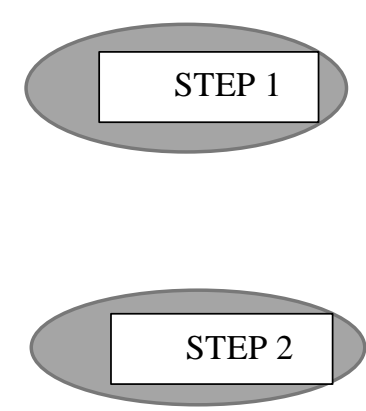

SELECTION FROM TITLE

Excluded articles:

$\mathbf{N}=630$

REASONS: Studies do not focus with adults. Full text not available.

STEP 3

SELECTION AFTER

READING THE
Direct Research on Pub

Med: keyword «metabolic syndrom 》 ARTICLES:

$\mathbf{N}=\mathbf{6 6 0 3 1}$
REASON: Do not
match the subiect

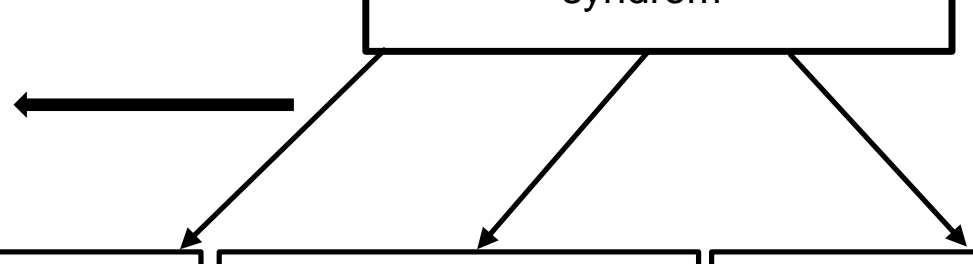

Keywords « metabolic syndrom + Psychosocial deprivation »

syndrom + Economic status »

Keyword « metabolic syndrom +

socioeconomic status »

Excluded articles: $\mathbf{N}=\mathbf{3 9}$

REASONS: Studies do not focus on the link between socioeconomic status and metabolic syndromes and/or raw data not available.

ADDITION

FROM INDIRECT

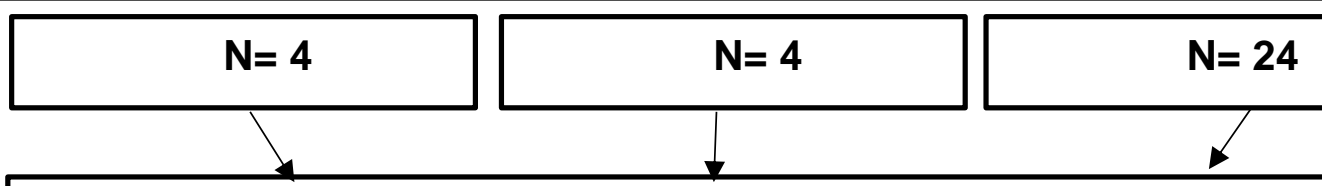

TOTAL INDIRECT RESEARCH N= 32

TOTAL (DIRECT + INDIRECT) $\mathrm{N}=73$ 
Figure 2 : Overall multivariate-adjusted OR

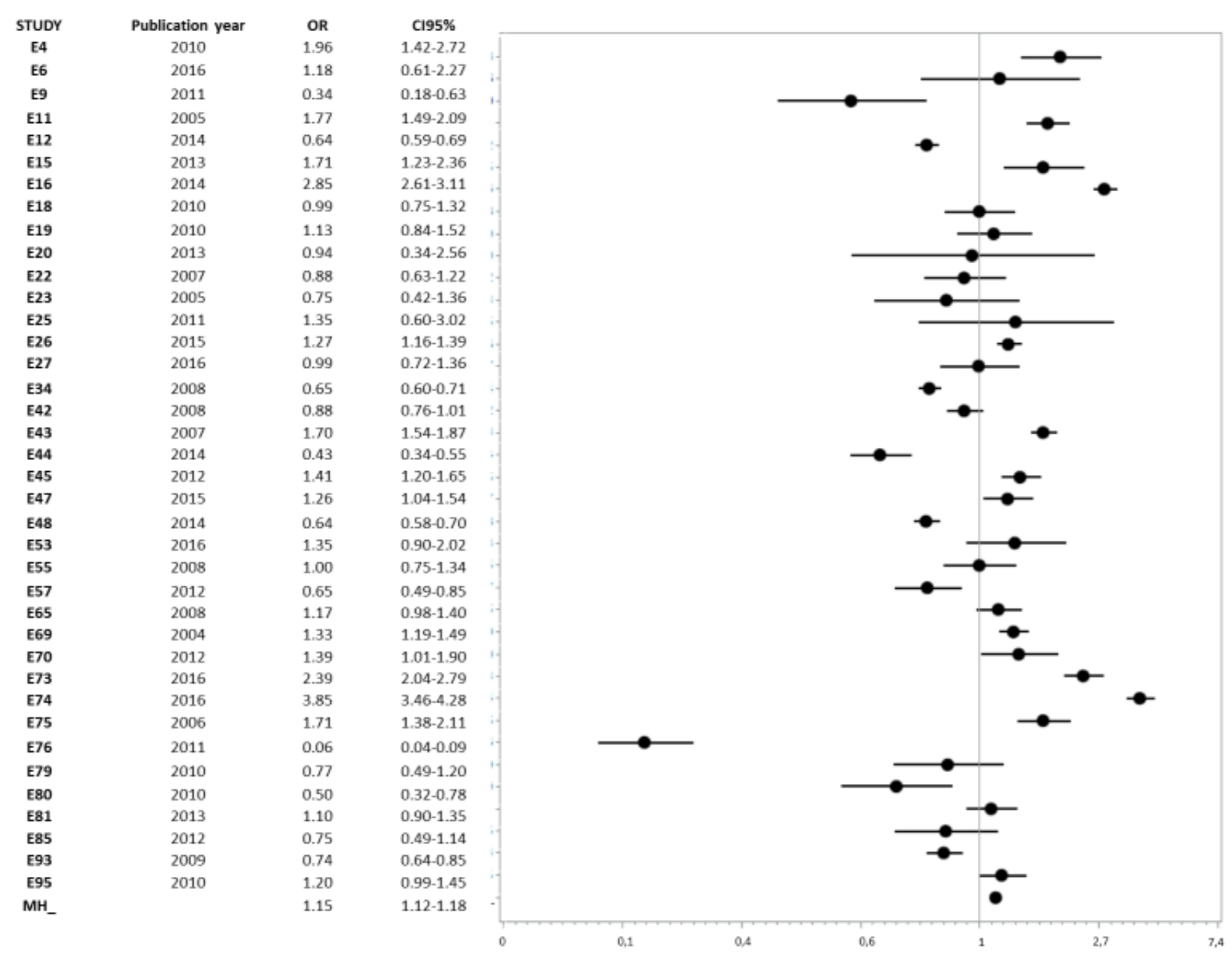


Figure 3 : Results of subgroup analysis

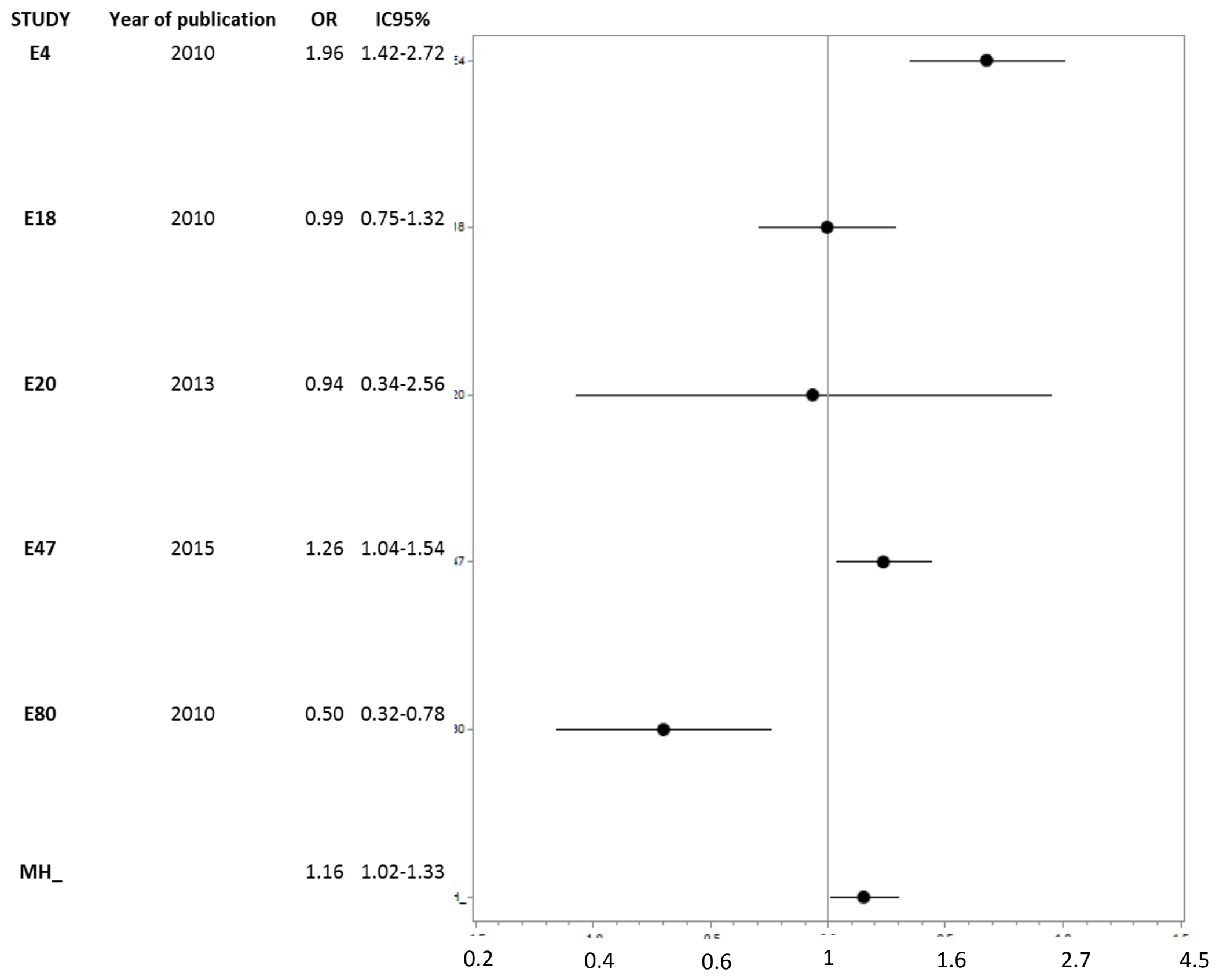


Figure 4: association between Mets and NCEP-ATPIII definition

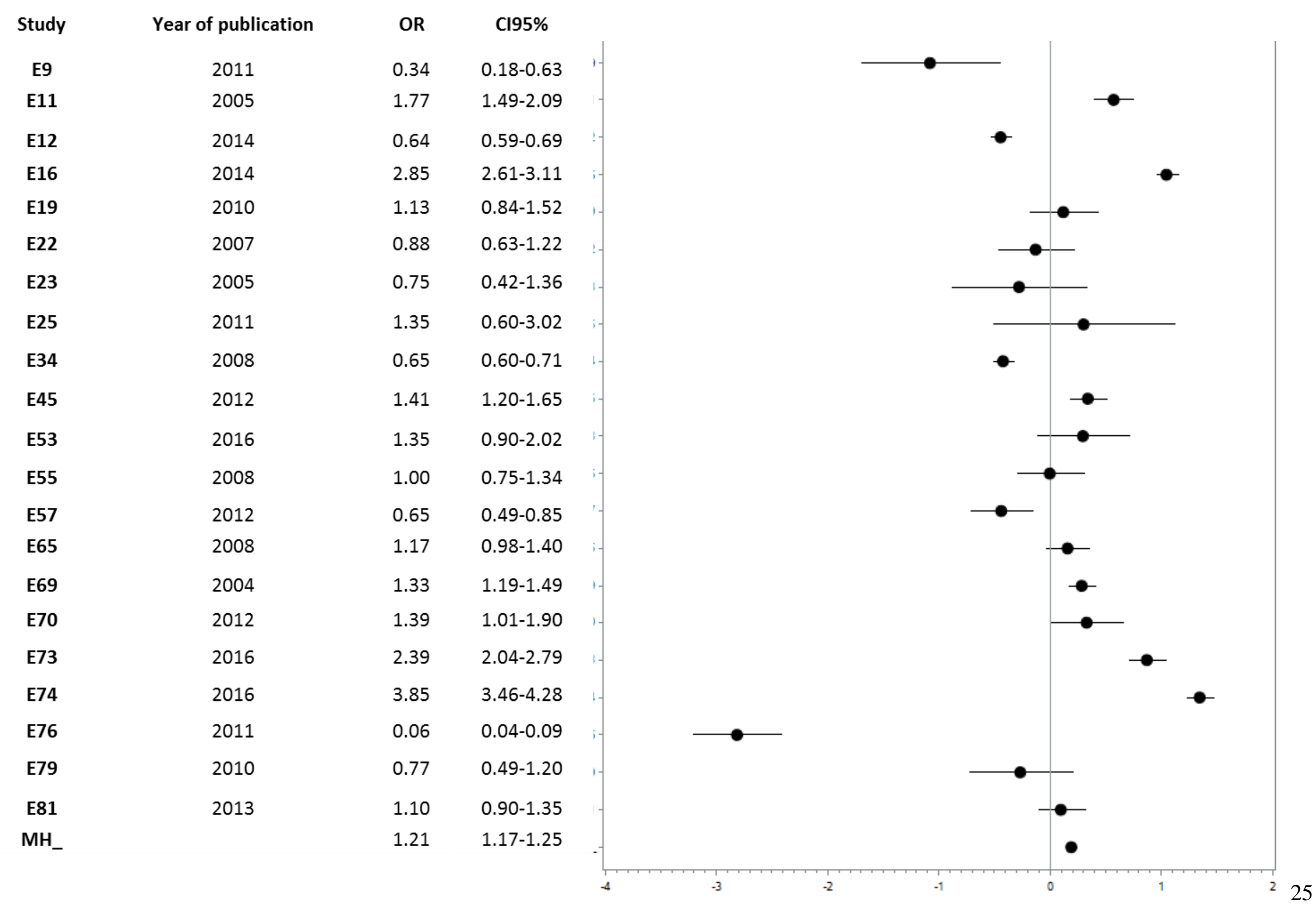


Figure 5 : association between Mets and other definitions

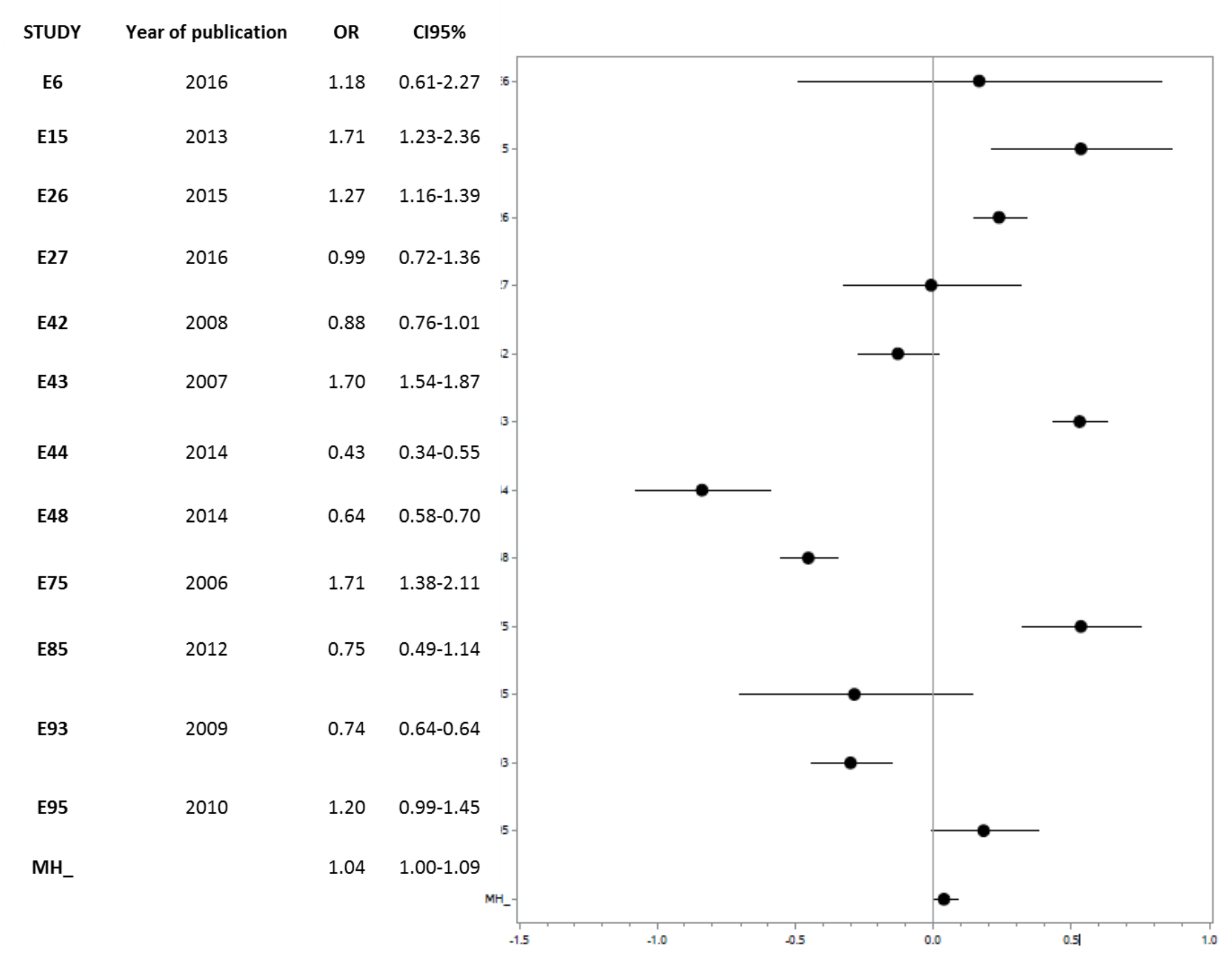




\begin{tabular}{|c|c|c|c|c|c|c|c|}
\hline Study & Year of publication & OR & $\mathrm{Cl} 95 \%$ & & & & \\
\hline E9 & 2011 & 0.34 & $0.18-0.63$ & E9- & & & \\
\hline E11 & 2005 & 1.77 & $1.49-2.09$ & E11- & & & \\
\hline E12 & 2014 & 0.64 & $0.59-0.69$ & E12- & & & \\
\hline E16 & 2014 & 2.85 & $2.61-3.11$ & E16- & & & \\
\hline E19 & 2010 & 1.13 & $0.84-1.52$ & E19 & & & \\
\hline E22 & 2007 & 0.88 & $0.63-1.22$ & E22 - & & & \\
\hline E23 & 2005 & 0.75 & $0.42-1.36$ & E23 & & & \\
\hline E25 & 2011 & 1.35 & $0.60-3.02$ & E25 - & & & \\
\hline E34 & 2008 & 0.65 & $0.60-0.71$ & E34 & & & \\
\hline $\mathrm{E} 45$ & 2012 & 1.41 & $1.20-1.65$ & E45- & & & \\
\hline E53 & 2016 & 1.35 & $0.90-2.02$ & E53- & & & \\
\hline E55 & 2008 & 1.00 & $0.75-1.34$ & E55- & & & \\
\hline E57 & 2012 & 0.65 & $0.49-0.85$ & E57- & & & \\
\hline $\mathrm{E} 65$ & 2008 & 1.17 & $0.98-1.40$ & E65- & & & \\
\hline $\mathrm{E} 69$ & 2004 & 1.33 & $1.19-1.49$ & E69- & & & \\
\hline E70 & 2012 & 1.39 & $1.01-1.90$ & E70- & & & \\
\hline E73 & 2016 & 2.39 & $2.04-2.79$ & E73 & & & \\
\hline E74 & 2016 & 3.85 & $3.46-4.28$ & E74 & & & \\
\hline E76 & 2011 & 0.06 & $0.04-0.09$ & E76- & 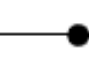 & & \\
\hline E79 & 2010 & 0.77 & $0.49-1.20$ & E79 - & & & \\
\hline E81 & 2013 & 1.10 & $0.90-1.35$ & E81- & & & \\
\hline \multirow[t]{3}{*}{$\mathrm{MH}_{-}$} & & 1.21 & $1.17-1.25$ & $\mathrm{MH}_{-}-$ & & & \\
\hline & & & & 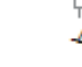 & -3 & -2 & -1 \\
\hline & & & & c & 0,1 & 0,4 & 0,6 \\
\hline
\end{tabular}




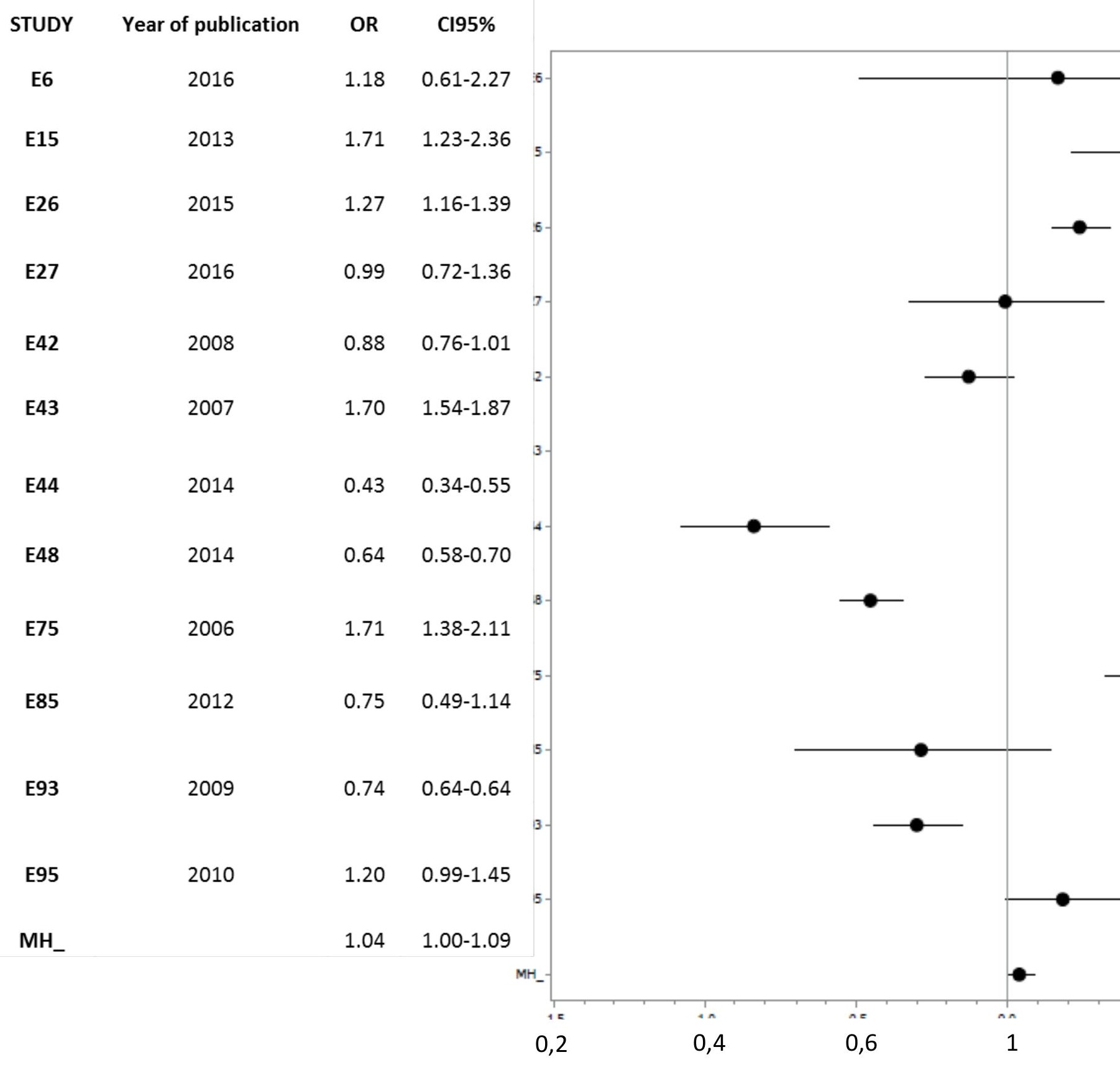

